\title{
Effects of Nano-Barium Sulfate on the Properties of Polybutylene Terephthalate/Polyethylene Terephthalate Composites
}

\author{
Beibei Li, ${ }^{1}$ Ling liu, ${ }^{1}$ Xuanlun Wang,${ }^{1 *}$ Yong Ma,,${ }^{2, *}$ Duo Pan,${ }^{3}$ Srihari Maganti, ${ }^{4}$ Benbin $\mathrm{Xu}^{5}$ and Zhanhu Guo ${ }^{4, *}$
}

\begin{abstract}
In this study, the nano barium sulfate $\left(\mathrm{Nano}-\mathrm{BaSO}_{4}\right)$ as an inorganic filler, polybutylene terephthalate (PBT)/polyethylene terephthalate (PET)/Nano-BaSO 4 composites were prepared by melt blending. The effect of Nano- $\mathrm{BaSO}_{4}$ on the properties of PBT/PET blends was studied by a thermal deflection temperature tester, differential scanning calorimeter, thermogravimetric analyzer, rotational rheometer, electronic universal tensile testing machine, pendulum impact testing machine, and other instruments. The results showed that when PBT: PET was set as 90:10 wt\% and Nano- $\mathrm{BaSO}_{4}$ content was $4 \mathrm{wt} \%$, the heat deflection temperature of the composites was the highest, which was $22.6 \%$ higher than that of the PBT/PET blends, and the heat resistance was the best. When the content of Nano- $\mathrm{BaSO}_{4}$ was $2 \mathrm{wt} \%$, the comprehensive mechanical properties of the material were the best.
\end{abstract}

Keywords: Polybutylene terephthalate; Polyethylene terephthalate; Nano Barium Sulfate; Composites; Modification.

Received: 08 November 2021; Revised: 18 January 2022; Accepted: 20 January 2022.

Article type: Research article.

\section{Introduction}

Polybutylene terephthalate (PBT) is a kind of thermoplastic engineering plastic with excellent comprehensive performance, ${ }^{[1]}$ which is formed by polycondensation of terephthalic acid and 1,4-butanediol, and its melting point can reach $225-235{ }^{\circ} \mathrm{C} .{ }^{[2]}$ It has many advantages such as good electrical and mechanical properties, outstanding hightemperature resistance, oil resistance, abrasion resistance, chemical corrosion resistance, fast crystallization rate, high crystallinity, easy forming, and processing, etc., ${ }^{[3,4]}$ so it is widely used in electronics connectors, lighting systems, and household appliances. ${ }^{[5]}$ With the development of the automotive industry, PBT materials have gradually replaced nylon materials and become the main choice for automotive electronic connectors. ${ }^{[6]}$ However, PBT has the shortcomings of being very sensitive to notch impact, poor dimensional

\footnotetext{
1 College of Materials Science and Engineering, Chongqing

University of Technology, Chongqing, 400054, China.

${ }^{2}$ School of Material Science and Engineering, Shandong University of Science and Technology, Qingdao 266590, China.

${ }^{3}$ Key Laboratory of Materials Processing and Mold, Ministry of

Education, National Engineering Research Center for Advanced

Polymer Processing Technology, Zhengzhou University, Zhengzhou,

China.
}

stability at high temperatures, and easy to warp, greatly reduced toughness of the material from the defects in the sample preparation process, and shortened service life of the part, all of which limit its application. ${ }^{[7-9]}$ The heat distortion temperature is also low. Therefore, glass fiber (GF) is usually used to modify PBT. The tensile strength, bending strength, impact strength, and heat deflection temperature (HDT) of the reinforced PBT material has been greatly improved, but the plastic parts are still prone to warpage. The crystallization rate of PBT is very fast, and the cooling rate is also very fast. During the injection molding process, it can be quickly cooled and molded. It only takes a few seconds to process small and thin parts. For larger parts, it can also be less than one minute. There are a large number of ester groups in the molecular chains of PBT resin, and the chain end contains a certain number of carboxyl groups, therefore, it is easily hydrolyzed in a high temperature and high humidity environment, causing the molecular chain to be broken, which directly affects the physical properties of the resin, ${ }^{[10,11]}$ these shortcomings all can be improved by modification.

PET is a linear thermoplastic polymer, that can maintain excellent physical and mechanical properties in a wide temperature range, has excellent fatigue resistance, aging resistance, electrical insulation, friction resistance, and excellent processing performance, and is stable in most 
inorganic acids and organic solvents. It has been widely used in the production of fibers, bottle flakes, films, engineering plastics, and other fields. ${ }^{[12-17]}$ Since PET has basically the same performance as PBT, it becomes a strong competitor of PBT when it comes out. There are only two $-\mathrm{CH}_{2}$ in the main molecular chain of PET, compared with PBT, the flexibility of the molecular chain is reduced, so PET has a higher heat distortion temperature, and good heat resistance and the cost is lower than PBT. However, the crystallization rate of PET is very slow, in the injection molding process, even small parts require a cooling time of about $30 \mathrm{~s}$. At the same time, due to its low fluidity, it is difficult to quickly fill in the entire mold cavity, resulting in increased defective products, therefore, the preparation of PET-containing parts requires appropriate process parameters.

Because the structures of PBT and PET are relatively similar, PBT and PET are often blended to combine their respective advantages and finally obtain a polymer material with a better comprehensive performance. The melting temperature difference between PBT and PET is only about $35{ }^{\circ} \mathrm{C}$, after the two are blended, PBT/PET composites of different mass ratios all have a single glass transition temperature value, and the blend system is considered to be compatible with the amorphous region. ${ }^{[18,19]}$ The crystallization rate of PBT is much greater than that of PET, and blending the two can solve the problem of a slow PET crystallization rate. The cost of raw materials for PET production is much lower than that of PBT, therefore, replacing part of PBT with PET under the premise of ensuring performance is also an effective way to save production costs. In recent years, the global polyester resin market has seen significant growth. According to research and market data, the growth rate of the PBT and PET resin market from 2014 to 2019 is about $7.3 \% .{ }^{[20]}$ A single polymer is often difficult to meet the diverse needs of the market, therefore, blending polymers has become an important way to solve the problem, and the blended system may achieve better performance. The PBT/PET blends can be used for spinning and engineering plastics, and it has good development prospects in the fields of textiles, home appliances, and automobiles. Many studies have used elastomers such as ethylene propylene rubber (EPR), ethylene propylene diene monomer (EPDM), styreneethylene/butylene-styrene (SEBS), and polyolefin elastomers (POE) to modify the PBT/PET composites, ${ }^{[21-25]}$ At present, the modification of pure PBT and PET is relatively extensive, but the modification of PBT/PET composites is less.

\footnotetext{
${ }^{4}$ Integrated Composites Laboratory (ICL), Department of Chemical \& Biomolecular Engineering, University of Tennessee, Knoxville, TN 37997, USA.

${ }^{5}$ Mechanical and Construction Engineering, Faculty of Engineering and Environment, Northumbria University, Newcastle upon Tyne NE1 8ST, UK.

*Email: wangxuanlun@cqut.edu.cn (X. Wang);

courage2010@126.com (Y. Ma); zguo10@utk.edu (Z. Guo)
}

Ucpinar et al. ${ }^{[26]}$ researched the effects of different compatibilizers on the properties of reduced graphene oxide (RGO) reinforced PET/PBT nanocomposites. The samples were prepared via melt compounding and injection molding methods. The Joncryl and glycidyl isooctyl polyhedral oligomeric silsesquioxane (GPOSS) were used as compatibilizers at different loading levels $(0.5 \%-4 \%)$. The thermal results showed that the compatibilizer addition caused small changes while rGO addition did not considerably affect the thermal stability of the blend. The glass transition temperature of the nanocomposite was significantly decreased with the addition of GPOSS. The tensile test indicated that the compatibilizers improved the mechanical performance of PET/PBT/rGO nanocomposites. Guo et al. ${ }^{[27]}$ researched the preparation of PBT/PET composites using carbon nanotubes (CNTs)/graphene nanoplatelets (GNPs) hybrid fillers by the melt blending process. Scanning electron microscopy showed that the CNTs/GNPs hybrid fillers had a better dispersion in the PBT/PET matrix, they could effectively cooperate to build filler network structure. The excellent synergistic effects of hybrid fillers could significantly improve the mechanical properties and thermal conductivity. When adding $2 \mathrm{phr}$ CNTs and $8 \mathrm{phr}$ GNPs simultaneously, Young's modulus was 1.2fold compared with PBT/PET blends. In addition, all hybrid composites with higher CNTs/GNPs weight ratios showed a higher electrical conductivity. Nano- $\mathrm{BaSO}_{4}$ is often used as an inorganic filler for polymers, with small particle size, large specific surface area, good wear resistance, and corrosion resistance, which can strengthen and toughen polymer materials; but its surface energy is high and its thermodynamic properties are unstable, therefore, Nano- $\mathrm{BaSO}_{4}$ is often surface modified before using it as an inorganic filler. To use of Nano- $\mathrm{BaSO}_{4}$ as fillers to modify PBT/PET blends has not been reported yet.

In this study, Nano- $\mathrm{BaSO}_{4}$ is used to modify the PBT/PET blend (where PBT: PET $=90: 10$ ). An aluminate coupling agent is used to modify the surface of barium sulfate and then used to fill the PBT/PET system. The effect of Nano-BaSO on the properties of $\mathrm{PBT} / \mathrm{PET}$ composites is verified by testing various properties of $\mathrm{PBT} / \mathrm{PET} / \mathrm{Nano}-\mathrm{BaSO}_{4}$ composites.

\section{Experimental \\ 2.1 Materials}

PBT (grade 1100-211M) was provided by Changchun Chemical Industry (Jiangsu) Co., LTD. PET (grade CR-8863) was provided by Dongguan Yongchang Plastic Raw Materials Co., LTD. Nano-BaSO4 was provided by Hunan Plastics Research Institute. Glycidyl methacrylate grafted ternary copolymer (brand PTW) was supplied by Dupont. Antioxidant 1010 was supplied by BASF, Germany. Polycarbonized diimine (grade K-1) was provided by Jining Bejia Polymer Materials Co., LTD. The aluminate coupling agent (grade DL411) was provided by Dongguan Kangjin New Materials Technology Co., LTD. 


\subsection{Preparation of $\mathrm{PBT} / \mathrm{PET} / \mathrm{Nano}^{-\mathrm{BaSO}_{4} \text { composites }}$}

The raw materials of PBT and PET were dried for 4 hours in a $120{ }^{\circ} \mathrm{C}$ blast drying oven (Shanghai Yiheng Scientific Instrument Co., Ltd, BPG-9070A, China), and Nano-BaSO 4 was dried for 2 hours in a $120^{\circ} \mathrm{C}$ blast drying oven. The Nano$\mathrm{BaSO}_{4}$ after drying was put into the high-speed mixer (Jiangsu White Bear Co., Ltd, SHR-10, China) for 5 minutes, and then an appropriate amount of aluminate coupling agent was added for the high-speed blending for 5 minutes. The mass ratio of Nano- $-\mathrm{BaSO}_{4}$ and aluminate coupling agent was 100:1. PBT, PET, and modified Nano-BaSO 4 were blended in a high-mixer at different ratios for 10 minutes (the ratio of PBT to PET was set to be 90:10 wt\%). The experimental formula is shown in Table 1. Then melt blending, extrusion granulation in the same direction twin screw extruder (Nanjing Ruiyafoss Polymer Equipment Co., Ltd, TSE-30A, L/D: 40:1, China), the temperature of each section of the barrel was set to $240{ }^{\circ} \mathrm{C}$ (head), $250{ }^{\circ} \mathrm{C}, 250^{\circ} \mathrm{C}, 250^{\circ} \mathrm{C}, 250^{\circ} \mathrm{C}, 250^{\circ} \mathrm{C}, 250^{\circ} \mathrm{C}, 240{ }^{\circ} \mathrm{C}$ $220^{\circ} \mathrm{C}, 200^{\circ} \mathrm{C}, 180^{\circ} \mathrm{C}$, screw speed $80 \mathrm{rpm}$, main feed speed $4 \mathrm{~Hz}$, granulated pellets were dried in a blast drying oven at $120^{\circ} \mathrm{C}$ for 4 hours to remove moisture. The dried pellets are injection molded in an injection molding machine (Donghua Machinery Co., Ltd, TTI-95G, China). The nozzle temperature was set to $260^{\circ} \mathrm{C}$, and the barrel temperature was $220 \sim 250^{\circ} \mathrm{C}$. The injection mold has one mold and two cavities, which are long strip splines (impact splines) and dumbbells (stretched splines).

Table 1. The experimental formula of Nano- $\mathrm{BaSO}_{4}$ filled PBT/PET blend (mass fraction).

\begin{tabular}{cccccc}
\hline $\begin{array}{c}\text { Sample } \\
\text { number }\end{array}$ & $\begin{array}{c}\mathrm{BaSO}_{4} \\
(\%)\end{array}$ & $\begin{array}{c}\mathrm{PBT} / \mathrm{PET} \\
(\%)\end{array}$ & $\begin{array}{c}\text { PTW } \\
(\%)\end{array}$ & $\begin{array}{c}\text { Polycarbodiimide Antioxidant } \\
(\%)\end{array}$ & $(\%)$ \\
\hline CB-1 & 1 & $90 / 10$ & 2 & 2 & 0.5 \\
$\mathrm{CB}-2$ & 2 & $90 / 10$ & 2 & 2 & 0.5 \\
$\mathrm{CB}-3$ & 3 & $90 / 10$ & 2 & 2 & 0.5 \\
$\mathrm{CB}-4$ & 4 & $90 / 10$ & 2 & 2 & 0.5 \\
CB-5 & 5 & $90 / 10$ & 2 & 2 & 0.5 \\
PBT/PET & - & $90 / 10$ & 2 & 2 & 0.5 \\
Pure PBT & - & $100 / 0$ & - & 2 & 0.5 \\
\hline
\end{tabular}

\subsection{Mechanical performance testing}

The tensile tests were conducted with an electromechanical universal testing machine (MTS systems Co., Ltd, CMT 6104, China) based on ASTM D638-10. The gauge length was 50 $\mathrm{mm}$, The width and thickness were $10 \mathrm{~mm}$ and $4 \mathrm{~mm}$, respectively, and the gauge rate was $20 \mathrm{~mm} / \mathrm{min}$.

The notched Izod impact strength was tested with a cantilever impact testing machine (MTS systems Co., Ltd, ZBC1400-B China) based on ASTM D256-10. The model of the pendulum bob was $4.4 \mathrm{~J}$. The spline size was $80 \mathrm{~mm} \times 10$ $\mathrm{mm} \times 4 \mathrm{~mm}$, and the depth of the spline notch was $2 \mathrm{~mm}$.

Five samples were measured for each component when the tensile tests and impact tests were operated, all the tests were conducted at $25{ }^{\circ} \mathrm{C}$.

\subsection{Thermal performance testing}

The heat deflection temperature (HDT) was tested according to the standard ASTM D648 (Chengde Jinjian Testing Instrument Co., Ltd, XRW-300, China). The B method with a bending stress of $0.45 \mathrm{MPa}$ was adopted, and the horizontal laying type was adopted, the heating rate was $120^{\circ} \mathrm{C} / \mathrm{h}$, the heat transfer medium was silicone oil, the sample size was 80 $\mathrm{mm} \times 10 \mathrm{~mm} \times 4 \mathrm{~mm}$, the span was $64 \mathrm{~mm}$.

Differential scanning calorimetry (DSC, TA Instruments, Q20, America) analysis was carried out by taking $3 \sim 5 \mathrm{mg}$ of each sample and heating it from room temperature to $250{ }^{\circ} \mathrm{C}$ in a nitrogen environment. The heating rate was $10^{\circ} \mathrm{C} / \mathrm{min}$, after eliminating the thermal history, the temperature was reduced to $25{ }^{\circ} \mathrm{C}$ at $10{ }^{\circ} \mathrm{C} / \mathrm{min}$, then increased to $250{ }^{\circ} \mathrm{C}$ at $10{ }^{\circ} \mathrm{C} / \mathrm{min}$, and finally dropped to room temperature.

Thermogravimetric (TG, TA Instruments, Q50, America) analysis was done by taking $5 \sim 8 \mathrm{mg}$ of each sample and heating it from room temperature to $600{ }^{\circ} \mathrm{C}$ in a nitrogen environment with a heating rate of $15^{\circ} \mathrm{C} / \mathrm{min}$.

\subsection{Rheological performance testing}

The test mode was frequency sweep, the test frequency range was $0.01 \sim 100 \mathrm{~Hz}$, the test temperature was $250{ }^{\circ} \mathrm{C}$, and the strain value was $1 \%$ (TA Instruments, AR1500ex, America).

\subsection{X-ray electron diffraction (XRD) analysis}

$\mathrm{Cu}$ target $\mathrm{K} \alpha$ rays were selected as the target material, and the sample was scanned at a speed of $0.33 \%$ at room temperature, and the scanning angle was $10-80^{\circ}$ (Spectris Instrument Systems Co., Ltd., PAN analytical Empyrean Series 2, UK).

\subsection{Micro-morphology Analysis}

A scanning electron microscope (SEM, Zeiss, IIGMA HDTM) was used to observe the microscopic morphology, and a thin layer of gold was sprayed on the sample for $1 \mathrm{~min}$, the scanning voltage was $5.00 \mathrm{kV}$.

\section{Results and discussion}

\subsection{Mechanical properties}

The relationship between the content of Nano- $\mathrm{BaSO}_{4}$ and the mechanical properties in the system is shown in Fig. 1. It can be seen that the tensile strength and impact strength of the system containing Nano-BaSO 4 are higher than those of pure PBT and PBT/PET. Fig. 1(a) shows the relationship between the Nano- $-\mathrm{BaSO}_{4}$ content and the tensile strength of the composite material. It can be seen from the figure that the tensile strength of the composite material in the range of $0-5 \%$ of Nano- $\mathrm{BaSO}_{4}$ shows a trend of increasing first and then decreasing. When the content of Nano- $\mathrm{BaSO}_{4}$ is $4 \%$, the tensile strength of the $\mathrm{PBT} / \mathrm{PET} / \mathrm{Nano}-\mathrm{BaSO}_{4}$ composites is the highest, i.e., $59.72 \mathrm{MPa}$, which is $11.6 \%$ higher than the $\mathrm{PBT} / \mathrm{PET}$ system. The reasons may be the small size of the nanoparticles and the large specific surface area. It has high physical and chemical activity and can be physically and chemically combined with the polymer chain segment, which 

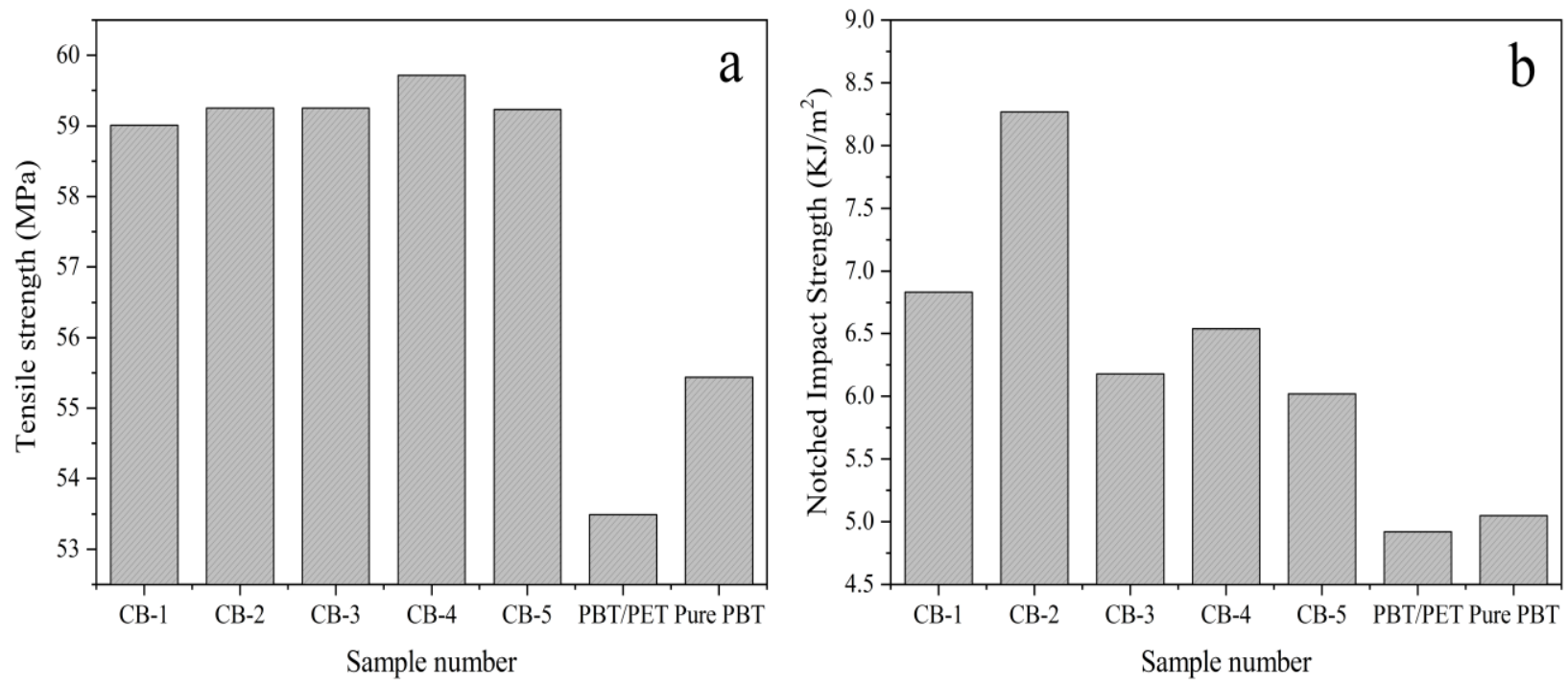

Fig. 1 (a) Tensile strength, and (b) notched impact strength of PBT/PET/Nano-BaSO 4 composites.

improves the binding force between the two phases. It requires more force to pull the material. However, when the content of Nano- $-\mathrm{BaSO}_{4}$ is too high, the Nano- $\mathrm{BaSO}_{4}$ is easy to agglomerate in the polymer matrix, leading to an increase in material defects, which leads to a decrease in the tensile strength of the composite material. Ucpinar et al..$^{[26]}$ researched the effect of reduced graphene oxide (RGO) on the properties of PET/PBT blends. The samples were prepared via melt compounding and injection molding methods. The yield strength of the PET/PBT(70/30) blend was $46 \mathrm{MPa}$ and the addition of $1 \% \mathrm{rGO}$ induced a rise in the yield strength of about $10 \%$. The tensile properties of this study were slightly better, and the cost of Nano-BaSO 4 was lower than rGO.

Figure 1(b) shows the relationship between the Nano$\mathrm{BaSO}_{4}$ content and the notched impact strength of the composite material. When the Nano- $\mathrm{BaSO}_{4}$ content is $2 \%$, the $\mathrm{PBT} / \mathrm{PET} / \mathrm{Nano}-\mathrm{BaSO}_{4}$ composites have the largest notched impact strength, i.e., $8.27 \mathrm{~kJ} / \mathrm{m}^{2}$, which is $68.1 \%$ higher than the PBT/PET system. This is because the rigidity of the inorganic particles provides a buffer for the stress of the matrix resin, and the Nano- $\mathrm{BaSO}_{4}$ has a large specific surface area and can be tightly combined with the matrix. When the material is subjected to an external force, the Nano-BaSO 4 particles can absorb a large amount of energy and can transfer the external stress well, so the comprehensive mechanical properties of the Nano- $\mathrm{BaSO}_{4}$ system are better, which are all greater than pure $\mathrm{PBT}$.

\subsection{Thermal properties}

\subsubsection{HDT analysis}

Figure 2(a) shows the HDT values and graphs of $\mathrm{PBT} / \mathrm{PET} / \mathrm{Nano}-\mathrm{BaSO}_{4}$ composites with different contents of Nano-BaSO 4 . It is shown that with the increase of Nano$\mathrm{BaSO}_{4}$ content, the HDT of the PBT/PET/Nano-BaSO 4 composites material also increases first and then decreases. When the Nano- $\mathrm{BaSO}_{4}$ content is $4 \%$, the thermal distortion temperature of the system reaches the maximum value of
$174.4{ }^{\circ} \mathrm{C}$, which is $21.8 \%$ higher than that of the PBT/PET system. When the Nano- $\mathrm{BaSO}_{4}$ content is $5 \%$, the thermal distortion temperature of the system is the lowest, which is $150.2^{\circ} \mathrm{C}$. This is because the surface polarity of Nano-barium sulfate is relatively large and can be adsorbed on the macromolecular chain of the matrix to increase the physical cross-linking point of the system, making the polymer chain difficult to move under heating, and the deformation of the composites material when heated is small. Thereby, it increases the thermal distortion temperature of the system. When the Nano- $\mathrm{BaSO}_{4}$ content is high, the uneven dispersion of Nano- $\mathrm{BaSO}_{4}$ particles in the polymer matrix leads to interface defects, which reduce the HDT of the $\mathrm{PBT} / \mathrm{PET} / \mathrm{Nano}-\mathrm{BaSO}_{4}$ composites.

\subsubsection{Thermal stability}

Figure 2(b) and Table 2 are the thermal weight loss curve and TG data of the PBT/PET/Nano-BaSO 4 composites. It can be seen that the $\mathrm{T}_{5}$ and $\mathrm{T}_{50}$ (Note: $\mathrm{T}_{5}$ represents the temperature when the system mass is decomposed by $5 \%$, and $\mathrm{T}_{50}$ is the temperature when the system mass is decomposed by $50 \%$ ) of the PBT/PET are lower than those of pure PBT, because the ester exchange reaction of PBT with PET causes the increase of internal defects in the system, and thus causes the thermal stability of PBT/PET to decrease. However, after adding Nano- $\mathrm{BaSO}_{4}$, the thermal decomposition temperature of the composite material rises again, indicating that adding Nano$\mathrm{BaSO}_{4}$ can improve the thermal stability of the composite material because of the surface polarity of Nano- $\mathrm{BaSO}_{4}$. It is relatively large and can be adsorbed on the macromolecular chain of the matrix, increasing the physical cross-linking point of the system, and making the polymer chain not easy to move under heating, thereby improving the thermal stability of the material. With the increase of the content of Nano-BaSO 4 , the temperature of each system is basically unchanged when the mass is decomposed by $5 \%$ and $50 \%$ and fluctuates in the range of $1{ }^{\circ} \mathrm{C}$. It shows that the additional amount of Nano- 

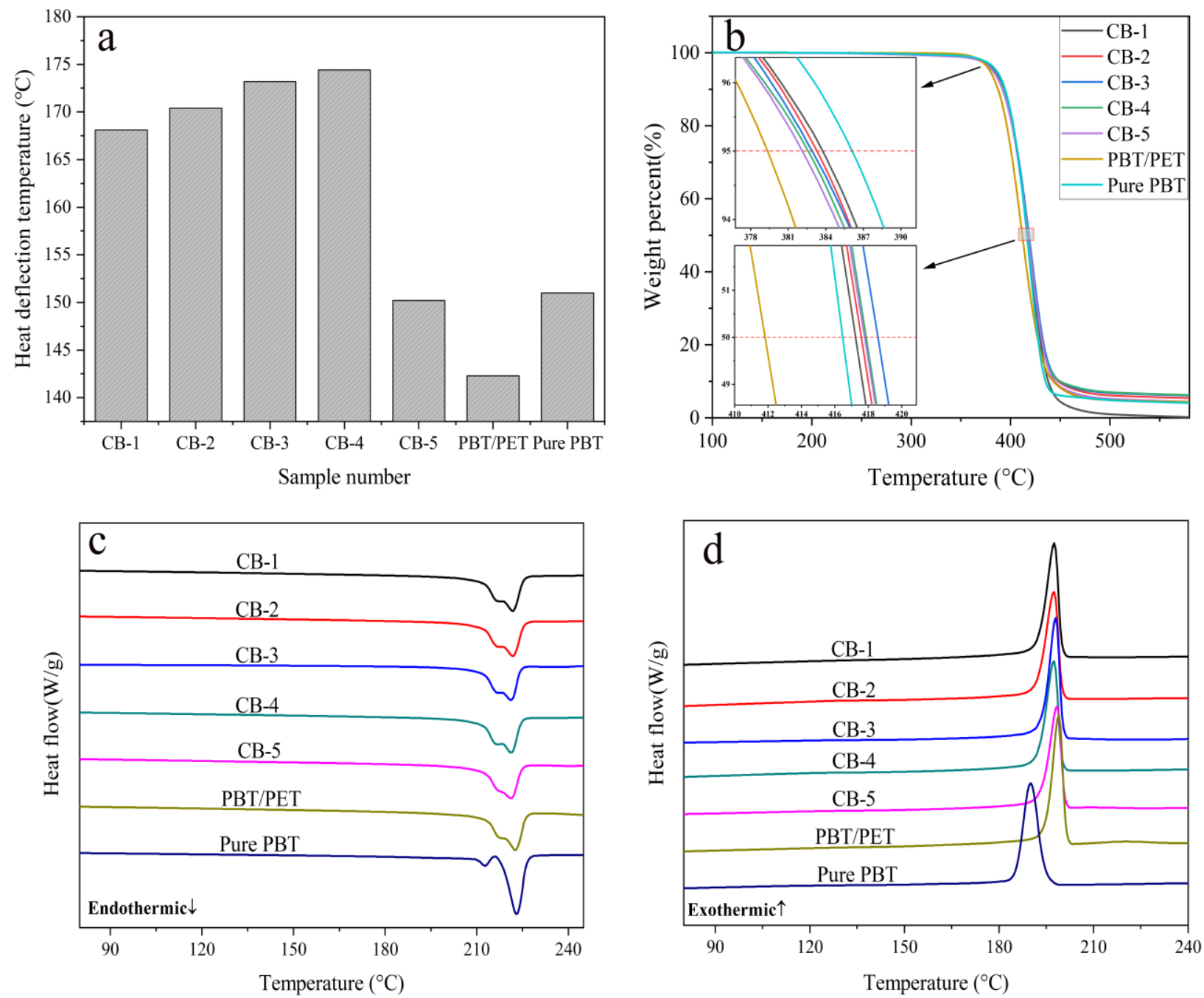

Fig. 2 (a) Heat deflection temperature, (b) thermal weight loss curves of PBT/PET/Nano-BaSO ${ }_{4}$ composites, DSC curves of the $\mathrm{PBT} / \mathrm{PET} / \mathrm{Nano}-\mathrm{BaSO}_{4}$ composites of (c) melting curves, and (d) crystalline curves.

$\mathrm{BaSO}_{4}$ has little effect on the thermal stability of the system.

Table 2. TG data of PBT/PET/Nano-BaSO 4 composites.

\begin{tabular}{cccc}
\hline Sample number & $\mathrm{T}_{5} /{ }^{\circ} \mathrm{C}$ & $\mathrm{T}_{50} /{ }^{\circ} \mathrm{C}$ & Residual ash \\
\hline CB-1 & 383.7 & 417.2 & 0.17 \\
CB-2 & 383.3 & 417.5 & 5.37 \\
CB-3 & 382.9 & 418.6 & 6.09 \\
CB-4 & 382.3 & 417.8 & 6.21 \\
CB-5 & 382.1 & 417.8 & 4.37 \\
PBT/PET & 379.5 & 412.0 & 4.38 \\
Pure PBT & 386.1 & 416.4 & 4.05 \\
\hline
\end{tabular}

\subsubsection{Differential scanning calorimetry (DSC) analysis}

The melting curve, crystallization curve, and DSC data of $\mathrm{PBT} / \mathrm{PET} / \mathrm{Nano}-\mathrm{BaSO}_{4}$ composites with different Nano$\mathrm{BaSO}_{4}$ contents are shown in Figs. 2(c), (d), and Table 3, respectively. It can be seen from Figs. 2(c), (d) that after adding PET, the melting temperature is basically unchanged, while the crystallization temperature is slightly increased.
Compared with pure PBT, the crystallization temperature of the PBT/PET system increases by $6.5^{\circ} \mathrm{C}$, this is because the ester exchange reaction of PBT with PET improves the compatibility of the system and increases the crystallization temperature. However, the product of the ester exchange reaction reduces the crystallinity of the system, at the same time, the ester exchange reaction also makes the molecular chain segment disorderly and arranged to a greater degree. Since the energy required to break the disordered state of the molecular chain is lower than that of the ordered state, the melting temperature of the composites has dropped. With the gradual increase of Nano- $\mathrm{BaSO}_{4}$, the crystallinity is gradually decreased. This is because Nano- $\mathrm{BaSO}_{4}$ hinders the movement of the molecular chain to a certain extent. The agglomeration behavior of Nano- $\mathrm{BaSO}_{4}$ will also destroy the regularity of the polymer chain to a certain extent, thereby affecting the crystallization behavior of the material. In this way, the crystallization of the materials of each formulation is not complete, so the crystallinity is reduced and the impact strength is improved compared with that of pure PBT. 
Table 3. DSC measurement data of PBT/PET/Nano-BaSO ${ }_{4}$ composites.

\begin{tabular}{cccccccc}
\hline Sample number & $\mathrm{T}_{\mathrm{ei}, \mathrm{m}} /{ }^{\circ} \mathrm{C}$ & $\mathrm{T}_{\mathrm{mm}} /{ }^{\circ} \mathrm{C}$ & $\Delta \mathrm{H}_{\mathrm{m}} /(\mathrm{J} / \mathrm{g})$ & $\mathrm{T}_{\mathrm{ei}, \mathrm{C}} /{ }^{\circ} \mathrm{C}$ & $\mathrm{T}_{\mathrm{cm}} /{ }^{\circ} \mathrm{C}$ & $\Delta \mathrm{H}_{\mathrm{c}} /(\mathrm{J} / \mathrm{g})$ & $\mathrm{X}_{\mathrm{c}} / \%$ \\
\hline CB-1 & 212.0 & 221.8 & 46.3 & 199.8 & 197.5 & 47.9 & 32.6 \\
$\mathrm{CB}-2$ & 211.9 & 221.8 & 46.4 & 199.9 & 197.4 & 46.4 & 32.7 \\
$\mathrm{CB}-3$ & 212 & 221.2 & 41.1 & 200.2 & 197.9 & 46.6 & 29.0 \\
CB-4 & 211.9 & 221.3 & 45.7 & 199.8 & 197.4 & 45.6 & 32.2 \\
CB-5 & 212.0 & 221.2 & 43.9 & 200.7 & 198.3 & 43.6 & 30.9 \\
PBT/PET & 212.7 & 222.6 & 48.5 & 201.2 & 198.9 & 45.0 & 34.1 \\
Pure PBT & 218.6 & 223.5 & 52.8 & 196.6 & 192.4 & 52.1 & 37.2 \\
\hline
\end{tabular}

(Among them, $\mathrm{T}_{\mathrm{e}, \mathrm{m}}$ is the melting start temperature, $\mathrm{T}_{\mathrm{mm}}$ is the melting temperature, $\triangle \mathrm{H}_{\mathrm{m}}$ is the melting endothermic enthalpy; $\mathrm{T}_{\mathrm{ei}, \mathrm{C}}$ is the crystallization start temperature, $T_{\mathrm{cm}}$ is the crystallization temperature, $\Delta H_{c}$ is the exothermic enthalpy of crystallization, $\mathrm{X}_{\mathrm{c}}$ is Crystallinity).

\subsection{Rheological properties}

It can be seen from Fig. 3(a) that as the content of Nano-BaSO 4 increases, the complex viscosity of the PBT/PET/Nano$\mathrm{BaSO}_{4}$ composites first decreases and then increases. This is because the aluminate coupling agent of the modified Nano$\mathrm{BaSO}_{4}$ has reduced the viscosity and lubrication. As the content of $\mathrm{Nano}_{-} \mathrm{BaSO}_{4}$ increases, the chain entanglement points of the PBT/PET/Nano-BaSO 4 composites increase, which hinders the flow of the melt, making the complex viscosity of the PBT/PET/Nano-BaSO composites increase, Therefore, the complex viscosity of the $\mathrm{PBT} / \mathrm{PET} / \mathrm{Nano}-\mathrm{BaSO}_{4}$ composites material first decreases and then increases. At the same time, as the shear frequency increases, the complex viscosity of each material also
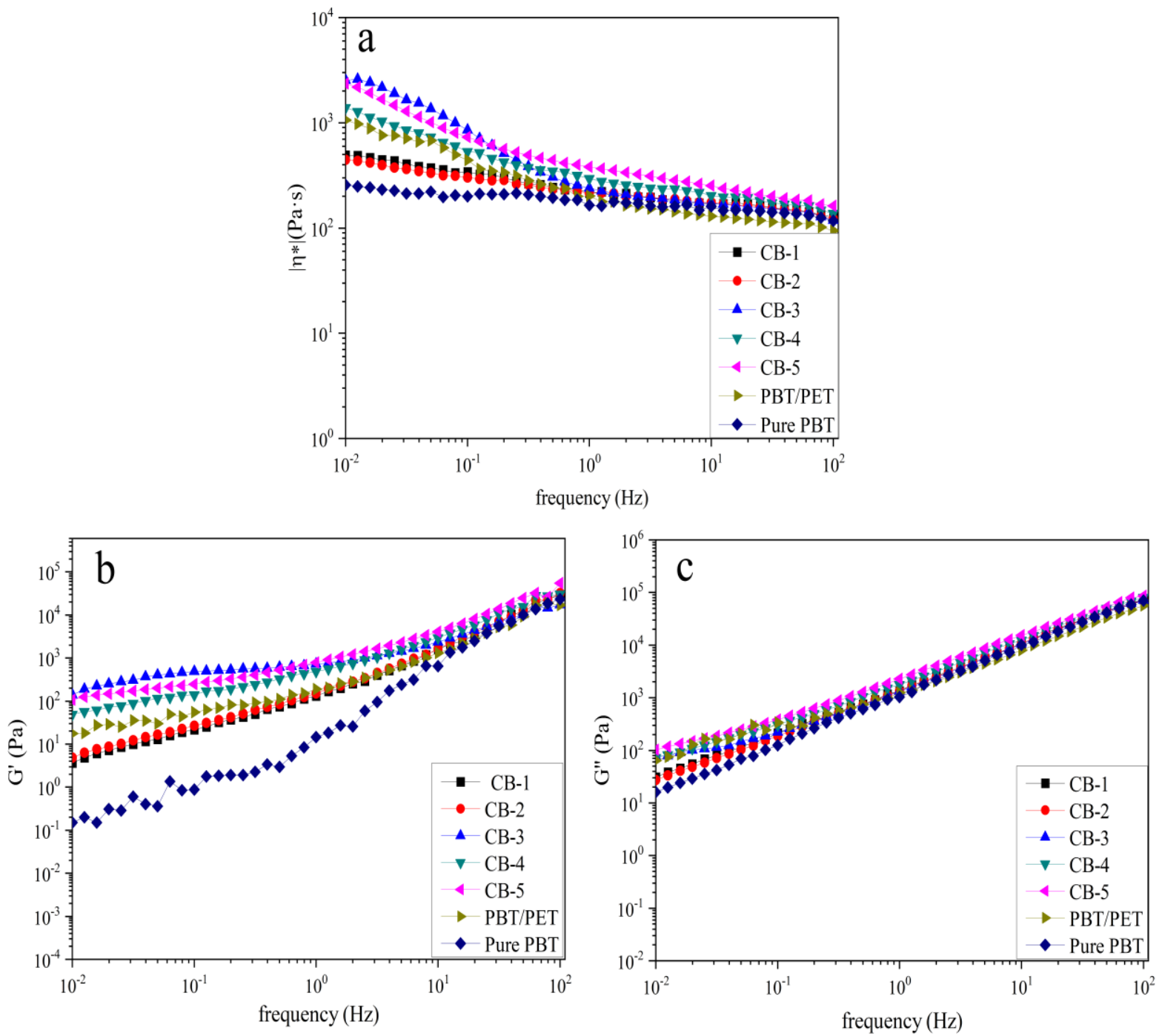

Fig. 3 The relationship between frequency and (a) complex viscosity, (b) storage modulus, and (c) loss modulus of PBT/PET/Nano$\mathrm{BaSO}_{4}$ composites. 
gradually decreases. This is the "shear thinning" phenomenon of high molecular polymers. This is because the polymer molecular chains are entangled with each other at a lower shear frequency and are not easy to move, so they appear to be relatively viscous. However, when the shear frequency becomes larger, these relatively unorganized molecular chains become easier to move because of the shear stress between the fluid layers, which reduces the mutual entanglement between the molecular chains, and the phenomenon of "untangling" occurs. The fluidity becomes better, showing a phenomenon of lower viscosity, which is further manifested as shear thinning. It can be seen from Figs. 3 (b)\&(c) that the storage modulus and loss modulus of the PBT/PET/Nano-BaSO ${ }_{4}$ composites both increase with the increase of frequency. This is because, at low frequencies, the molecular chains of the composites are in the relaxation stage. Energy is low, therefore, the storage modulus and loss modulus are both small, and when the frequency is high, the shear rate is large, and the molecular chains are oriented under the action of shearing force. Therefore, the storage modulus and the loss modulus all increase. The storage modulus $\left(\mathrm{G}^{\prime}\right)$ refers to the energy stored due to the elastic deformation of the material during the deformation process, reflects the elastic component of the material, and characterizes the stiffness of the material. The loss modulus $\left(\mathrm{G}^{\prime \prime}\right)$ refers to the energy lost by viscous deformation, reflects the viscous component of the material, and characterizes the damping of the material. As the hardness of Nano- $\mathrm{BaSO}_{4}$ particles is relatively large, as the content of Nano-BaSO 4 increases, the rigidity of the composite material gradually increases, resulting in a gradual increase in $\mathrm{G}^{\prime}$. As the content of Nano- $\mathrm{BaSO}_{4}$ increases, the damping force on the molecular motion will increase with the enhancement of the interface between the polymer matrix and the filler particles. Therefore, as the content of Nano- $\mathrm{BaSO}_{4}$ increases, the damping force between the molecular chains gradually increases, causing the movement of the molecular chains to be blocked. Thus, the $\mathrm{G}^{\prime \prime}$ gradually increases.

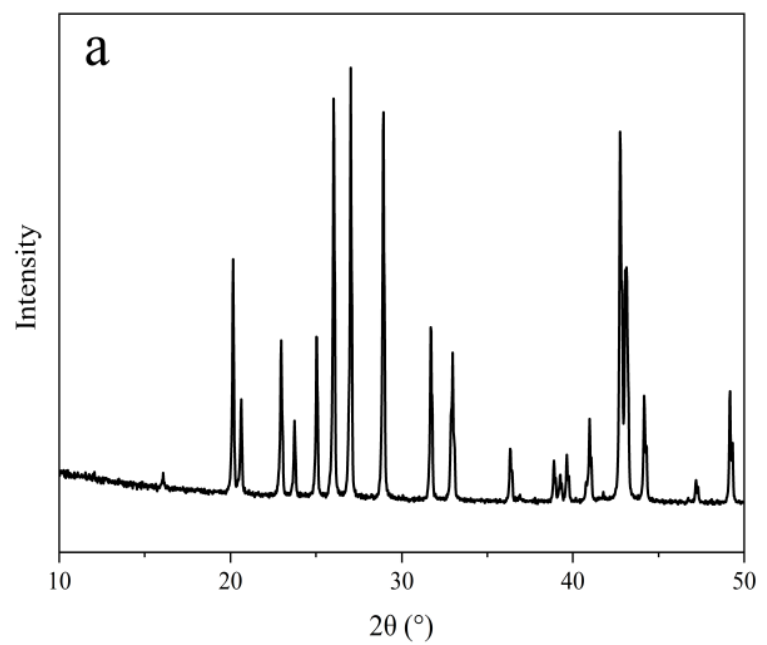

\subsection{X-ray electron diffraction (XRD) analysis}

Figure 4 shows the X-ray diffraction patterns of Nano$\mathrm{BaSO}_{4}$ powder and $\mathrm{PBT} / \mathrm{PET} / \mathrm{Nano}-\mathrm{BaSO}_{4}$ composites. From Fig. 4 , it can be seen that the PBT/PET/Nano- $\mathrm{BaSO}_{4}$ composites containing Nano- $\mathrm{BaSO}_{4}$ all show the diffraction

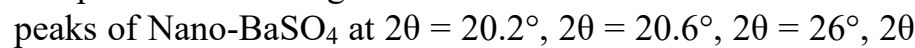
$=27^{\circ}, 2 \theta=28.9^{\circ}, 2 \theta=31.7^{\circ}, 2 \theta=33^{\circ}, 2 \theta=42.8^{\circ}$. Their diffraction peak is consistent with the characteristic peaks of Nano-BaSO 4 . Careful observation shows that the diffraction peaks of the composites are basically not shifted. Therefore, the addition of Nano-BaSO 4 has no significant effect on the composites structure of the PBT/PET/Nano- $\mathrm{BaSO}_{4}$ composites.

\subsection{Morphologies of the Fractured Surfaces}

The impact section morphology of PBT/PET/Nano-BaSO ${ }_{4}$ composites with different contents of Nano- $\mathrm{BaSO}_{4}$ was observed using a scanning electron microscope. As shown in Fig. 5(a) of the cross-sectional morphology of pure PBT, it can be seen that the cross-section is relatively flat and smooth, with local delamination, showing the characteristics of brittle fracture. Fig. 5(b) is the cross-sectional morphology of the PBT/PET composite material, the cross-section is slightly rougher than pure PBT, and the larger granular substance in the cross-section is PET, it can be seen that the PET is evenly dispersed in the PBT and the interface is tightly bonded. Figs. $5(\mathrm{c} \sim \mathrm{g})$ is the cross-sectional morphology of the $\mathrm{PBT} / \mathrm{PET} / \mathrm{Nano}-\mathrm{BaSO}_{4}$ composite material with $1 \% \sim 5 \%$ Nano-BaSO 4 , the small white particles in the cross-section are Nano- $\mathrm{BaSO}_{4}$ particles, and there are pits on the cross-section, the pits left by Nano- $\mathrm{BaSO}_{4}$ particles when the spline is broken. When $1 \%$ Nano- $\mathrm{BaSO}_{4}$ is added, there are fewer Nano- $\mathrm{BaSO}_{4}$ particles and pits in the section. With the gradual increase of Nano- $\mathrm{BaSO}_{4}$, the pits gradually increase, when $2 \% \sim 4 \%$ Nano- $\mathrm{BaSO}_{4}$ is added, Nano- $\mathrm{BaSO}_{4}$ particles and pits are more evenly distributed. When $5 \%$ of $\mathrm{Nano}^{-\mathrm{BaSO}_{4} \text { was }}$ added, the Nano- $\mathrm{BaSO}_{4}$ particles began to agglomerate locally and large pits appeared, which proved that the Nano-BaSO 4 particles agglomerated in the polymer matrix.

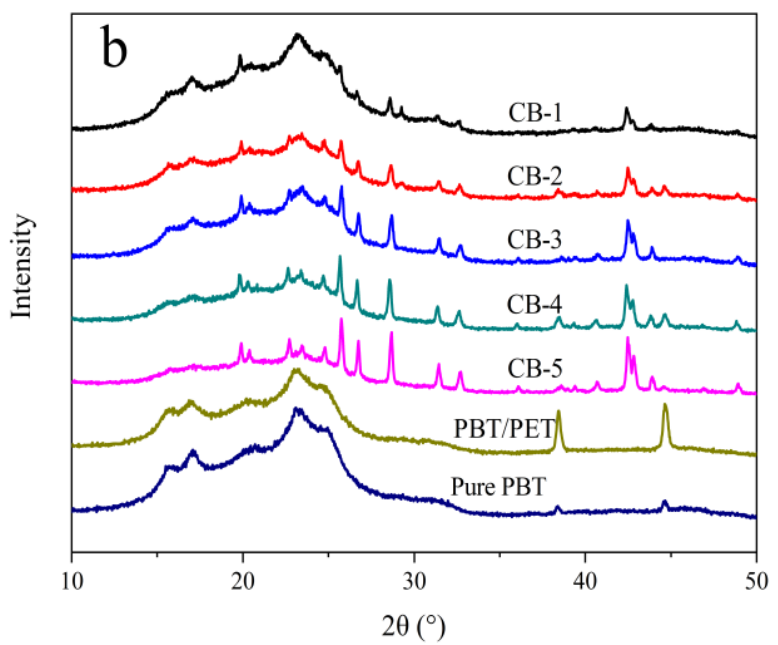

Fig. 4 X-ray diffraction pattern of (a) Nano-BaSO 4 , and (b) PBT/PET/Nano-BaSO 4 composites. 


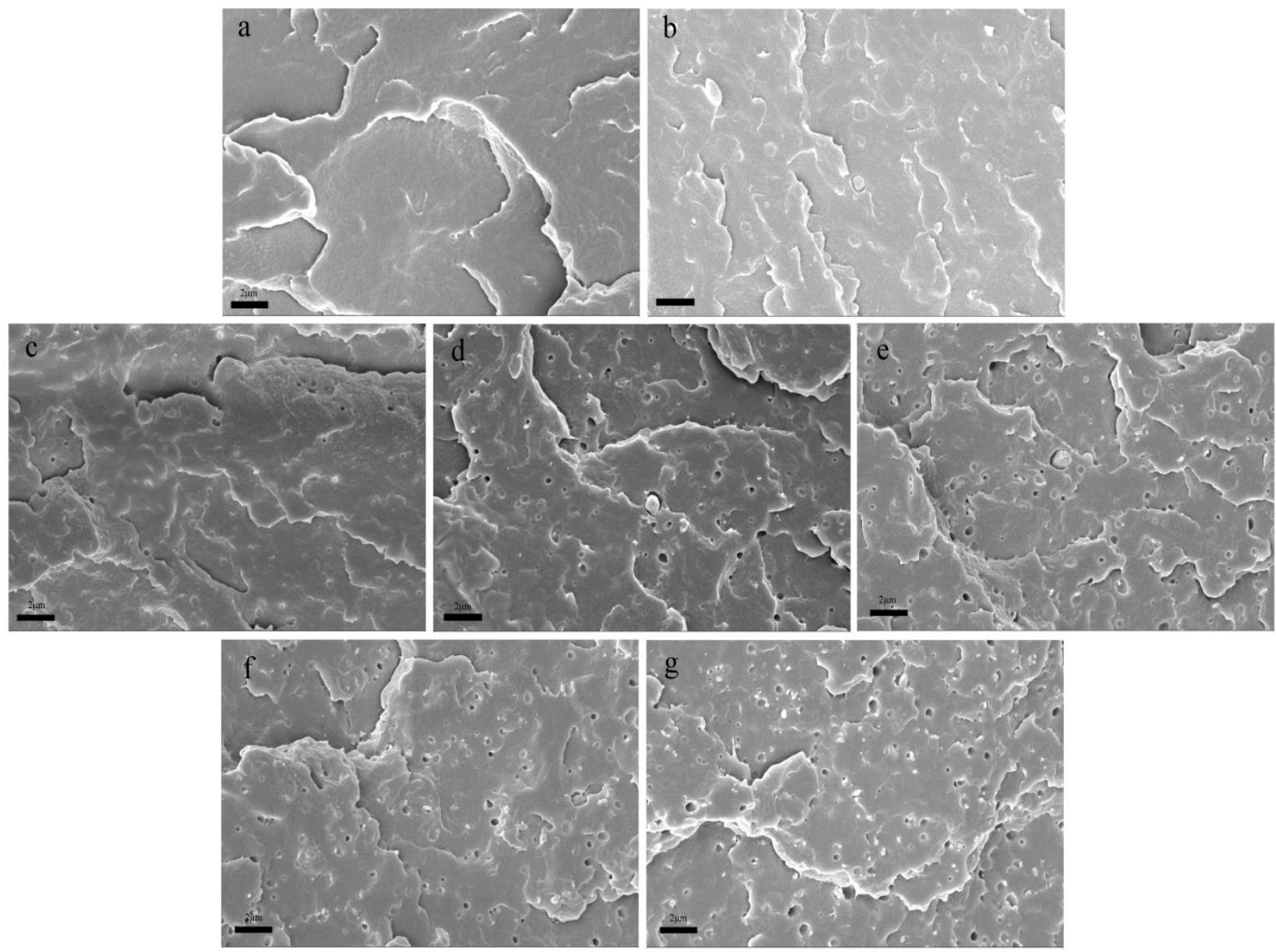

Fig. 5 SEM image of (a) PBT, (b) PBT/PET, (c) CB-1, (d) CB-2, (e) CB-3, (f) CB-4, (g) CB-5.

\section{Conclusion}

An appropriate amount of Nano- $\mathrm{BaSO}_{4}$ can increase the HDT of the PBT/PET system. When the content of Nano-BaSO was $4 \%$, the HDT of the composite was $22.6 \%$ higher than that of the PBT/PET system. Nano- $\mathrm{BaSO}_{4}$ can improve the mechanical properties of the PBT/PET system. When the content of Nano- $\mathrm{BaSO}_{4}$ was $4 \%$, the tensile strength of the composite material was $11.6 \%$ higher than that of the PBT/PET system. When the content of Nano-BaSO 4 was $2 \%$, the impact strength of the composite material was $68.1 \%$ higher than that of the PBT/PET system. As the content of Nano-BaSO${ }_{4}$ increases, the crystallinity of the composite material decreases slightly. Nano- $\mathrm{BaSO}_{4}$ did not affect the thermal stability of the composite material. With the increase of the content of Nano- $\mathrm{BaSO}_{4}$, the composite viscosity, storage modulus and loss modulus of composite materials gradually increase. A proper amount of nano-barium sulfate can be uniformly dispersed in the PBT/PET matrix. When the matrix contains more nano- $\mathrm{BaSO}_{4}$, agglomeration will occur. This study provides a way to modify the property of PBT/PET blends.

\section{Acknowledgments}

Financially Supported by the technical innovation and application development project of Chongqing Science and Technology Bureau (Grant No. cstc2019jscx-msxmX0045).

\section{Conflict of Interest}

There is no conflict of interest.

\section{Supporting Information}

Not applicable.

\section{References}

[1] R. S. Stein, A. Misra, Journal of Polymer Science, 1980, 18, 327-342, doi: 10.1002/pol.1980.180180215.

[2] R. Y. Wang, X. D. Chen, Q. J. Xu, Advanced Material Research, 2014, 860, 855-861, doi: 10.4028/www.scientific.net/AMR.860-863.855.

[3] N. Avramova, Polymer, 1995, 36, 801-808, doi: 10.1016/0032-3861(95)93111-x.

[4] W. Zhang, C. Zheng, Y. Zhang, W. Guo, Polymers, 2019, 11, 1784, doi: 10.3390/polym11111784.

[5] J. Che, B. Luan, X. Yang, Material Letters, 2005, 59, 16031609, doi: 10.1016/j.matlet.2004.09.057.

[6] T. Zhao, J. Ai, P. Wang, W. Tong, C. Ding, Y. Cen, M. Zhang, Advanced Industrial and Engineering Polymer Research, 2019, 2, 203-208, doi: 10.1016/j.aiepr.2019.09.005.

[7] H. Bai, Y. Zhang, Y. Zhang, X. Zhang, W. Zhou, Polymer Testing, 2005, 24, 235-240, doi: 10.1016/j.polymertesting.2004.08.002. 
[8] A. Zabaleta, I. González, J. I. Eguiazábal, J. Nazábal, European Polymer Journal, 2009, 45, 466-473, doi: 10.1016/j.eurpolymj.2008.10.022.

[9] R. N. Baxi, S. U. Pathak, D. R. Peshwe, Polymer Journal, 2011, 43, 801-808, doi: 10.1038/pj.2011.69.

[10] J. R. Martin, R. J. Gardner, Polymer Engineering and Science, 1981, 21, 557-565, doi: 10.1002/pen.760210908.

[11] Y. Yamamoto, H. Hoshina, H. Sato, Macromolecules, 2021, 54, 1052-1062, doi: 10.1021/acs.macromol.0c02049.

[12] T. Tiso, T. Narancic, R. Wei, E. Pollet, N. Beagan, K. Schröder, A. Honak, M. Jiang, S. T. Kenny, N. Wierckx, R. Perrin, L. Avérous, W. Zimmermann, K. O'Connor, L. M. Blank, Metabolic Engineering, 2021, 66, 167-178, doi: 10.1016/j.ymben.2021.03.011.

[13] Nisticò R, Polymer Testing, 2020, 90, 106707, doi: 10.1016/j.polymertesting.2020.106707.

[14] L. Xiao, D. C. Sun, T. L. Niu, Y. W. Yao, Phosphorus Sulfur, 2014, 189, 1564-1571, doi: 10.1080/10426507.2014.884092.

[15] Y. Peng, M. Niu, R. Qin, B. Xue, M. Shao, High Performance Polymers, 2020, 32, 871-882, doi: 10.1177/095400832091436.

[16] Y. Yang, M. Niu, J. Dai, J. Bai, B. Xue, Y. Song, Y. Peng, Fire and Materials, 2018, 42, 794-804, doi: 10.1002/fam.2634.

[17] D. Adner, M. Helmy, T. Otto, J. Schellenberg, A. Schadewald, Fire and Materials, 2019, 43, 169-174, doi: 10.1002/fam.2682.

[18] Y. Yu, K.-J. Choi, Polymer Engineering \& Science, 1997, 37, 91-95, doi: 10.1002/pen.11648.

[19] G. Aravinthan, D. D. Kale, Journal of Applied Polymer Science, 2005, 98, 75-82, doi: 10.1002/app.22017.

[20] Zhang Y, Mech. Eng. Tech., 2015, 4, 28-71, doi: 10.12677/met.2015.41004.

[21] W. Loyens, G. Groeninckx, Polymer, 2002, 43, 5679-5691, doi: 10.1016/S0032-3861(02)00472-X.

[22] W. Loyens, G. Groeninckx, Polymer, 2003, 44, 123-136, doi: 10.1016/s0032-3861(02)00743-7.

[23] P. Jin-Gyu, K. Dong-Hyun, K. D. Suh, Journal of Applied Polymer Science, 2000, 78, 2227-2233, doi: 10.1002/10974628(20001213)78:12<2227:AID-APP210>3.0.CO;2-0.

[24] C. Jun, Y. Wei, L. Zhengying, H. Rui, Journal of Material Science, 2004, 39, 4049-4051, doi: 10.1023/B:JMSC.0000031493.09473.a9.

[25] Z.-Z. Yu, M.-S. Yang, S.-C. Dai, Y.-W. Mai, Journal of Applied Polymer Science, 2004, 93, 1462-1472, doi: 10.1002/app.20592.

[26] B. Ucpinar Durmaz, C. Ozturk, A. Aytac, Polymer Engineering \& Science, 2020, 60, 2606-2618, doi: 10.1002/pen.25498.

[27] Z. Gao, Q. Dong, M. Shang, B. Shentu, C. Wu, Journal of Applied Polymer Science, 2022, 139, 51733, doi: 10.1002/app.51733.

\section{Author Information}

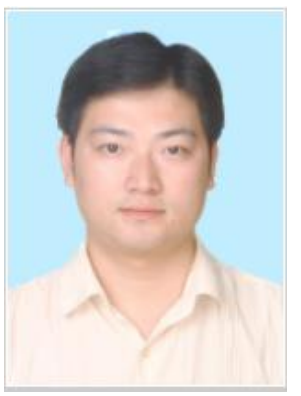

Wang Xuanlun, professor and master tutor of the School of Materials Science and Engineering, Chongqing University of Technology, member of the Expert Committee of Chongqing New Materials Industry Federation, his research fields are polymer material modification and functional polymer materials, and he has been engaged in the processing of polymer materials for a long time. with modification.

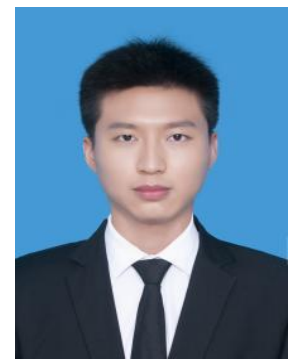

Li Beibei, a graduate student at the School of Materials Science and Engineering, Chongqing University of Technology, is mainly engaged in the processing and modification of plastics.

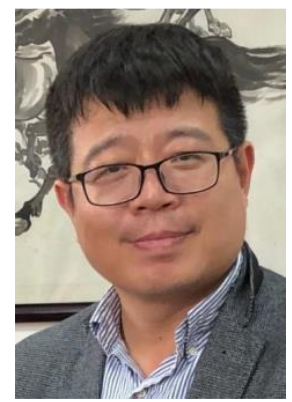

Zhanhu Guo earned his Ph.D. degree in chemical engineering from Louisiana State University in 2005. He received his three-year postdoctoral training in mechanical and aerospace engineering at the University of California Los An-geles. $\mathrm{He}$ is a Professor in Chemical and Biomolecular Engineering directs the Integrated Composites Laboratory at The University of Tennessee, Knoxville. His current research interests are in the areas of optoelec-tronic, electric, and magnetic materials for solar cells, catal-ysis, sensing, and electronics.

Publisher's Note: Engineered Science Publisher remains neutral with regard to jurisdictional claims in published maps and institutional affiliations. 